of nitrogen gas and regeneration of three molecules of hydrazine, or it may be that the $\mathrm{N}_{2} \mathrm{H}_{3}$ - ions discharge upon hydrazine molecules with formation of $\mathrm{N}_{2} \mathrm{H}_{2}=$, or $\mathrm{N}_{2} \mathrm{H}=$ ions which then react yielding as before nitrogen gas and hydrazine. Any of these three sorts of ions might still further be considered to discharge upon hydrazine yielding the ion $\mathrm{N}_{2}==$ which, finally discharging on the anode, would be directly converted into nitrogen gas. In any event one atom of nitrogen would be liberated at the anode for each atom of copper deposited on the coulometer cathode.

This theoretical ratio $\mathrm{Cu}: \mathrm{N}$ is approximately realized in the first eight experiments in which the concentration of the electrolyte with respect to sodium hydrazide is relatively low. The excess of nitrogen found as well as the presence of hydrogen is probably to be accounted for either by the failure of the regeneration of hydrazine to take place quantitatively or by the slight catalytic decomposition of the solvent.

In Expts. 9 to I3, inclusive, in which the concentration was distinctly higher, the ratio of copper to nitrogen was much lower, averaging I : 2.4. This points to more extensive decomposition either of the discharged anions or of the solvent under these conditions.

\title{
Summary.
}

In the present investigation it has been shown that:

(I) Sodium derivatives of hydrazine may be prepared by the action of anhydrous hydrazine upon either metallic sodium or sodium amide.

(2) Solutions of sodium hydrazide in anhydrous hydrazine readily conduct the current, yielding in general nitrogen and hydrogen at both anode and cathode. For each gram atom of copper deposited on the coulometer cathode from I.I to I.5 g. atoms of nitrogen gas were liberated at the anode when the electrolyte was rather dilute. With a more highly concentrated solution, however, the ratio $\mathrm{Cu}: \dot{\mathrm{N}}$ varied from I :2.I to I : : 2.6.

This investigation was undertaken at the suggestion of Professor A. W. Browne and was carried out with his coöperation.

CORNELI UNIVERSITY,

ITAACA, N. $\mathbf{Y}$.

[Contribution from Department of Physical Chemistry, Chemical Laboratories OF THE UNIVERSITY OF MARbURG.]

THE SOLUBILITY OF CERTAIN DIFFICULTLY SOLUBLE SILVER SALTS.

By A. ThIzL.

Received July 1, 1914.

In an article of the above title in This Jotrnal, 30, 68 (1908), which has only recently come to my attention, A. E. Hill describes several determinations of the ratio of the solubilities $\mathrm{AgCl}, \mathrm{AgBr}, \mathrm{AgI}$ and $\mathrm{AgCNS}$. 
He proceeds by determining the concentration of the respective anions in the solution in equilibrium with two of the salts as solid phases. Upon putting a value for silver chloride obtained in another manner into the equation, he can indirectly determine the solubility of the above-named salts on the basis of the solubility relations found according to his method. The procedure employed by Hill has repeatedly been applied for similar purposes before this and it will give reliable results in all of those cases in which the fundamental assumption is complied with, namely, that the two salts are present in the pure state as the solid phases. Apparently the author has not taken the earlier original literature upon this subject into account sufficiently and, consequently, has overlooked the fact that the necessary assumption which makes the method applicable does not apply in a number of the cases considered. Thus, F. W. Kuester and I have been able to show ${ }^{1}$ that $\mathrm{AgBr}$ and $\mathrm{AgI}$, as well as $\mathrm{AgBr}$ and $\mathrm{AgCNS}$, form solid solutions, and that the solid phases in these cases, provided the concentrations of the two species of anions in the solution do not differ too greatly from one another, consist of the two saturated solid solutions. The measurements of $\mathrm{Hill}$ on the systems $\mathrm{AgBr}+\mathrm{AgI}$ and $\mathrm{AgBr}+\mathrm{Ag}-$ CNS do therefore in no case give the ratio of the solubilities of the pure salts, but that of the partial solubilities of these salts from the solid phase present. As one can conclude from the tables given in the case of the bromide-iodide mixture, this solid phase consisted partly of the two saturated solutions and also of an unsaturated solid phase; in the case of the bromide-thiocyanate mixture it always consisted of the two saturated solid solutions ( $\mathrm{AgBr}$ in $\mathrm{AgCNS}$ and vice versa).

As far as the silver iodide is concerned the effect produced upon the calculated solubility is not great, since the silver bromide which is dissolved in the silver iodide does not affect the solubility of the latter in water very greatly. When fresh portions of silver bromide are added one probably obtains a false equilibrium of great inactivity, the position of which does not vary much from that of the unstable system $\mathrm{AgBr}_{\text {pure }}$ $+\mathrm{AgI}_{\text {pure. }}$. On the other hand, the influence of an admixture of the second component on the solubility of a solid phase is very great in the system $\mathrm{AgBr}+\mathrm{AgCNS}$, and if the results obtained by Hill nevertheless agree well with those obtained by other methods the agreement is to be considered accidental.

If the system $\mathrm{AgCl}+\mathrm{AgBr}$ had been examined in the same manner, in which case an uninterrupted series of solid solutions is formed, a striking inconsistency of the solubility relations would have at once been apparent, showing the method to be inapplicable.

Among the influences responsible for the accidental agreement of the values of Hill, one might, perhaps, assume the fact that the author has

1. Z. anorg. Chem., 19, 8I (1899); 24, I (1900); 33, I29 (1902). 
taken as the standard for the solubility of silver chloride an old result of Kohlrausch and Rose and further does not make use of the more recent values, ${ }^{1}$ known at the time, for comparison with the other solubilities calculated by him. If this is done, conditions are not changed markedly. The evidence of solubility determinations, according to a method based upon assumptions insufficiently complied with, is not to be valued too highly in the cases under discussion. Yet one may draw the conclusion from the results obtained in the system $\mathrm{AgBr}+\mathrm{AgCNS}$, that the partial solubilities of the two components, as compared with the solubilities of the pure substances, are diminished in practically the same ratio. This follows from the fact that the solubilities of the two solid components in one another, in mol percentages, are of the same magnitude.

marburg a/L Germany.

[CONTRIBUTIONS FROM THE HAVEMEYER ChEMICAL LABORATORY, NEW YORK UNIVERSITY.]

\section{THE RELATIVE SOLUBILITY OF CERTAIN SILVER SALTS.}

By Arthur E. HiLl.

Received December 24, 1914.

The foregoing paper ${ }^{2}$ by Professor Thiel contains five specific criticisms of my publication on "The Relative Solubility of the Silver Halides and Silver Sulfocyanate." 3 They may be stated briefly as follows: (I) the publication criticised shows unfamiliarity with the work of Küster and Thiel, ${ }^{4}$ who have shown that solid solutions exist in the cases of $\mathrm{AgBr}$ and $\mathrm{AgCNS}$ and of $\mathrm{AgBr}$ and $\mathrm{AgI} ;(2)$ if equilibrium experiments had been made with the salts $\mathrm{AgCl}$ and $\mathrm{AgBr}$, the method would have been found unsuited for solubility calculations; (3) the correct value obtained for the solubility ratio of $\mathrm{AgBr}$ and $\mathrm{AgCNS}$ is accidental; (4) the correct value obtained for the solubility ratio of $\mathrm{AgBr}$ and $\mathrm{AgI}$ is due probably to a false equilibrium, and finally, (5) all agreement shown may be due to the use in the calculations of the old value obtained by Kohlrausch and Rose for the solubility of silver chloride, instead of more recent values to which Thiel refers. Brief comment may be made on each of these criticisms.

The first criticism must be accepted as justified. I did not know of Küster and Thiel's work on these solid solutions until after the publication of my paper. In this instance it seems to me fortunate that I was unacquainted with their work at that time, for if I had read the publications I might possibly have been discouraged from using these salts in my research. In that event the equilibrium method might not have been ap-

1 F. Kohlrausch, $Z$. physik. Chem., 44, I97 (1903); 50, 355 (1908); W. Böttger, Ibid., 46, 52 I (I903).

2 This Journal.

${ }^{3}$ Ibid., 30, 68 (1908).

4. anorg. Chem., 19, 81 (1899); 24, I (1900); 33, I29 (1902). 